\title{
Evaluation of Hibiscus esculentus Linn. on the Mechanical and Disintegration Properties of Paracetamol Tablets
}

\section{A.S. MANN*, N.K. JAIN AND M.D. KHARYA}

Department of Pharmaceutical Sciences, Dr. H. S. Gour University, Sagar 470003, (M.P) India.

The effects of mucilage obtained from the ripe fruits of Hibiscus esculentus Linn. (Malvaceae) on the mechanical and disintegration properties of paracetamol tablets were investigated against gum acacia as a standard binding agent. The effects of the nature and concentration of the mucilage binder and the relative density of the tablet on the tensile strength, brittle fracture index and disintegration time of the tablets were investigated. Relative density, concentration and nature of binder had the greatest effects on tensile strength, brittle fracture index and disintegration time, respectively. Increasing, the concentration of mucilage from $2.5 \%$ to $10.0 \% \mathrm{w} / \mathrm{w}$, and increasing relative density of the tablet from 0.70 to 0.80 led to an increase in tensile strength and disintegration time, but a decrease in brittle fracture index. Tablets formulated with $\boldsymbol{H}$. esculentus mucilage had lower tensile strength and disintegration time values than those containing gum acacia, and exhibited less lamination and capping. The nature and concentration of binder had the highest interaction among the factors studied. In conclusion, Hibiscus esculentus mucilage could be useful as an alternative binding agent to gum acacia, especially where faster disintegration is required and lamination and capping are of concern.

Key words: Hibiscus esculentus, mucilage, binding agent, paracetamol, tensile strength, brittle fracture index, disintegration time

\section{INTRODUCTION}

Mucilage from established sources is being used extensively as a binder and disintegrant in tablet formulations. Recently efforts have been expended in developing new excipients from local/indigenous sources to cater for the ever increasing demand from pharmaceutical industries. Ripe fruits of Hibiscus esculentus are rich in mucilage [1]. This study was conducted to investigate the mucilage for tablet formulations by studying its binding and disintegrating properties. The present work focused on the relative quantitative effects of the nature $(\mathrm{N})$ and concentration $(\mathrm{C})$ of binder and the relative density (RD) of the tablets on the mechanical and disintegration properties of paracetamol tablets, using a factorial experimental design [2], which has previously proved useful in the analysis of the quantitative individual and interaction effects of various formulation factors on tablet properties [3-5].
Tensile strength (TS) and brittle fracture index (BFI) were used to assess the mechanical properties of the tablets [5-8]. Paracetamol, an important analgesic and antipyretic agent, was chosen for the present work due to its poor compression properties which necessitate the use of a binding agent among other excipients to form good quality tablets.

\section{EXPERIMENTAL}

\section{Materials}

Paracetamol BP, lactose BP, gum acacia and magnesium stearate were obtained from Ranbaxy Labs (Gurgaon, Delhi, India). The excipient mucilage was extracted from the ripe fruits of H. esculentus in the laboratory [9].

\section{Preparation of granules}

In a Kenwood planetary mixer (Kenwood Electronics UK Ltd, Herts, UK), $250 \mathrm{~g}$ batches

\footnotetext{
*Author to whom correpondence may be addressed.
} 
of a basic formulation of paracetamol (82\% $\mathrm{w} / \mathrm{w}), H$. esculentus mucilage $(10 \% \mathrm{w} / \mathrm{w})$, and lactose $(8 \% \mathrm{w} / \mathrm{w})$ were dry-mixed for $5 \mathrm{~min}$ and moistened with $40 \mathrm{ml}$ of distilled water or appropriate amounts of mucilage to produce granules containing different concentrations of the mucilage as a binder. Massing was continued for $5 \mathrm{~min}$ and the wet masses granulated by passing manually through a number 12 mesh sieve $(1400 \mu \mathrm{m})$. The granules were dried in a hot air oven for $18 \mathrm{~h}$ at $50{ }^{\circ} \mathrm{C}$, sieved through a number 16 mesh sieve $(1000 \mu \mathrm{m})$ and stored in airtight containers.

\section{Preparation of tablets}

Tablets of weight $500 \mathrm{mg}$ were prepared from $500-1000 \mu \mathrm{m}$ granules by compression with predetermined loads on a Carver hydraulic hand press (Model C, Carver Inc, Menomonee Falls, WI) for $30 \mathrm{~s}$ on $10.5 \mathrm{~mm}$ dies and flat punches lubricated with a $2 \% \mathrm{w} / \mathrm{v}$ dispersion of magnesium stearate in ether:ethanol (1:1). Tablets with a $1.59 \mathrm{~mm}$ diameter hole at the center were made using appropriately designed punches $[6,10]$. The tablets were stored over silica gel for $24 \mathrm{~h}$ to allow for elastic recovery and hardening, and to prevent falsely low yield values. The weights (W) and dimensions were then determined.

\section{Tablet evaluation}

The bulk density, $(\rho B)$ of each tablet was calculated from the equation

$$
\rho_{B}=\frac{W}{\pi r^{2} h}
$$

Where $\mathrm{W}$ is the weight $(\mathrm{g}), \mathrm{r}$ is the radius $(\mathrm{cm})$ and $\mathrm{h}$ is the thickness $(\mathrm{cm})$ of the tablet.

The relative density (RD) of the tablet was then calculated from the equation

$$
\mathrm{RD}=\frac{\rho_{\mathrm{B}}}{\rho_{\mathrm{S}}}
$$

Where $\rho S$ is the particle density $\left(\mathrm{gcm}^{-3}\right)$ as determined by the pycnometer method with xylene as the displacement fluid.

\section{Testing parameters}

The tensile strength (TS) of the normal tablets and apparent tensile strength of those containing a hole $\left(\mathrm{TS}_{0}\right)$, were determined at room temperature $\left(25 \pm 2 \quad{ }^{\circ} \mathrm{C}\right)$ by diametral compression [11] using a Kanara hardness tester (Kanara Industrial Corporations, Bombay, India) and by applying the equation:

$$
\mathrm{TS}\left(\text { or } \mathrm{TS}_{0}\right)=\frac{2 \mathrm{~F}}{\pi \mathrm{dt}}
$$

Where TS (or $\mathrm{TS}_{0}$ ) is the tensile strength of the tablet $\left(\mathrm{MNm}^{-2}\right), \mathrm{F}$ is the load $(\mathrm{MN})$ needed to cause fracture, $d$ is the tablet diameter $(\mathrm{m})$, and $\mathrm{t}$ is the tablet thickness (m). Results were taken only from tablets which split cleanly into 2 halves without any sign of lamination. All measurements were made in quadruplicate and the results given are the means of 4 determinations.

The BFI (brittle fracture index) of the tablets was calculated using equation

$\mathrm{BFI}=\frac{\mathrm{TS}-1}{\mathrm{TS}_{0}}$

Where TS is the tensile strength of the tablets without a hole and $\mathrm{TS}_{0}$ is the apparent tensile strength of the tablets when a hole is present.

\section{Disintegration Tests}

The disintegration times, DT, of the tablets was determined in distilled water at $37 \pm 0.5^{\circ} \mathrm{C}$ using a Veego disintegration tester (Veego Scientific Devices, Mumbai, Maharashtra, India). All measurements were made in quadruplicate and the results given are the means of 4 determinations.

\section{Factorial experimental design}

To study the effect of nature of mucilage binder $(\mathrm{N})$, concentration of mucilage binder $(\mathrm{C})$, and relative density (RD) on the mechanical and disintegration properties of paracetamol tablets, the experiments were performed in a factorial 
design, which involved the application of simple statistics [2]. The basis of the experimental design was that each of the 3 variables was used at a high level (subscript $\mathrm{H}$ ) and a low level (subscript L). The number of experiments in the design was $2^{3}=8$.

Using the above nomenclature the various combinations of the variables used in the design were as follows:

\section{$\mathrm{N}_{L} \mathrm{C}_{\mathrm{L}} \mathrm{DL}, \mathrm{N}_{L} \mathrm{CH}_{\mathrm{H}} \mathrm{DL}, \mathrm{N}_{\mathrm{L}} \mathrm{CHRDH}_{\mathrm{H}}, \mathrm{N}_{\mathrm{L}} \mathrm{ClRDH}_{\mathrm{H}}$}

$\mathrm{NHCl}_{\mathrm{L}}$ L., NHCHRDL, NHChRDh, $\mathrm{N}_{\mathrm{H}} \mathrm{ClRDH}_{\mathrm{H}}$

$\mathrm{N}_{\mathrm{L}}=$ Nature of binder (H. esculentus)

$\mathrm{N}_{\mathrm{H}}=$ Nature of binder (Gum acacia)

$\mathrm{C}_{\mathrm{L}}=$ Concentration of $H$. esculentus binder (2.5

$\% \mathrm{w} / \mathrm{w})$

$\mathrm{C}_{\mathrm{H}}=$ Concentration of Gum acacia binder (10.0 $\% \mathrm{w} / \mathrm{w})$

$\mathrm{RD}_{\mathrm{L}}=$ Relative density $(0.70)$

$\mathrm{RD}_{\mathrm{H}}=$ Relative density $(0.80)$

By grouping the results into several sets, it was possible to assess the effects that each of the 3 variables had separately on the mechanical and disintegration properties of the tablets and to determine whether the variables were interacting or acting independently of each other.

The effects of increasing N, from its "low" level to its "high" level on the various parameters were found by summing all the results (TS or BFI or DT) of samples containing a high level of $\mathrm{N}$ and subtracting the sum of the results of samples containing low levels of $\mathrm{N}$ according to the equation

$1 / 4\left\{\left(\mathrm{~N}_{\mathrm{H}} \mathrm{C}_{\mathrm{L}} \mathrm{RD}_{\mathrm{L}}+\mathrm{N}_{\mathrm{H}} \mathrm{C}_{\mathrm{H}} \mathrm{RD}_{\mathrm{L}}+\mathrm{N}_{\mathrm{H}} \mathrm{C}_{\mathrm{H}} \mathrm{RD}_{\mathrm{H}}+\right.\right.$ $\left.\mathrm{N}_{\mathrm{H}} \mathrm{C}_{\mathrm{L}} \mathrm{RD}_{\mathrm{H}}\right)-\left(\mathrm{N}_{\mathrm{L}} \mathrm{C}_{\mathrm{L}} \mathrm{RD}_{\mathrm{L}}+\mathrm{N}_{\mathrm{L}} \mathrm{C}_{\mathrm{H}} \mathrm{RD}_{\mathrm{L}}+\right.$ $\left.\left.\mathrm{N}_{\mathrm{L}} \mathrm{C}_{\mathrm{H}} \mathrm{RD}_{\mathrm{H}}+\mathrm{N}_{\mathrm{L}} \mathrm{C}_{\mathrm{L}} \mathrm{RD}_{\mathrm{H}}\right)\right\}$

The amount by which the result of this treatment departed from 0 was a quantitative measure of the effect of $\mathrm{N}$ on the values of the relevant parameter. Similar expressions were used for finding the effects of $\mathrm{C}$ and $\mathrm{RD}$.

To determine whether there was any interaction between 2 variables, the TS (or BFI or DT) results of the combinations in which they appear together at either "high" or "low" levels were summed and the sum of other combinations subtracted from this to obtain the interaction coefficient. For example, for $\mathrm{N}$ and $\mathrm{C}$ the equation used was

$1 / 4\left\{\mathrm{~N}_{\mathrm{L}} \mathrm{C}_{\mathrm{L}} \mathrm{RD}_{\mathrm{L}}+\mathrm{N}_{\mathrm{L}} \mathrm{C}_{\mathrm{L}} \mathrm{RD}_{\mathrm{H}}+\mathrm{N}_{\mathrm{H}} \mathrm{C}_{\mathrm{H}} \mathrm{RD}_{\mathrm{H}}+\right.$ $\left.N_{H} C_{H} R D_{L}\right)-\left(N_{L} C_{H} R D_{L}+N_{L} C_{H} R D_{H}+N_{H} C_{L} R D_{L}\right.$ $\left.+\mathrm{N}_{\mathrm{H}} \mathrm{C}_{\mathrm{L}} \mathrm{RD}_{\mathrm{H}}\right)$ \}

A result of 0 indicated no interaction, but if the interaction coefficient was significantly varied from 0 , it was concluded that the 2 variables concerned were interacting with each other. The extent of variation from 0 is a measure of the magnitude of interaction [2]. Similar expressions were used for estimating the interactions between $\mathrm{N}$ and $\mathrm{RD}$ and between $\mathrm{C}$ and RD.

\section{Statistical analysis}

Statistical analysis to compare the individual and interaction effects of the formulation variables on the mechanical and disintegration properties of the tablets was done with the Kruskal-Wallis test, a nonparametric multiple comparison test, using the computer software Graphpad Prism 4 (GraphPad Software Inc, San Diego, CA). Individual differences between the formulations were performed using the Dunn's multiple comparison tests. Significancy was set at $\mathrm{p} \leq 0.05$.

\section{RESULTS AND DISCUSSION}

Representative plots of $\log$ TS, BFI, and DT versus RD for paracetamol tablets containing 2.5 $\% \mathrm{w} / \mathrm{w}$ of the mucilages as binding agents are presented in figures 1,2 and 3 . The values of TS, BFI, and DT at 2 selected relative density values of 0.7 and 0.8 used for the factorial experiment, representative of the range of relative density values normally achieved for commercial paracetamol tablets, are presented in Table 1. These values were used to calculate the individual and interaction coefficients for the variables using the relevant equations. The individual and interaction coefficient values are presented in Table 2. These values provide a clear indication of the quantitative effects of the 
3 variables studied on the TS, BFI, and DT of the paracetamol tablets.

Table 1. Tensile strength, brittle fracture index and disintegration times of paracetamol tablets for factorial experimental design

\begin{tabular}{llll}
\hline $\begin{array}{l}\text { Variables and } \\
\text { Combination } \\
\text { Codes }\end{array}$ & $\begin{array}{l}\text { TS } \\
\left(\mathbf{M N m} \mathbf{- n}^{-2}\right)\end{array}$ & BFI & $\begin{array}{l}\text { DT } \\
(\text { min })\end{array}$ \\
\hline $\mathrm{N}_{\mathrm{L}} \mathrm{C}_{\mathrm{L}} \mathrm{R}_{\mathrm{L}}$ & 0.633 & 0.463 & 0.234 \\
$\mathrm{~N}_{\mathrm{L}} \mathrm{C}_{\mathrm{L}} \mathrm{R}_{\mathrm{H}}$ & 0.916 & 0.446 & 0.346 \\
$\mathrm{~N}_{\mathrm{L}} \mathrm{C}_{\mathrm{H}} \mathrm{R}_{\mathrm{L}}$ & 0.479 & 0.421 & 0.276 \\
$\mathrm{~N}_{\mathrm{L}} \mathrm{C}_{\mathrm{H}} \mathrm{R}_{\mathrm{H}}$ & 0.213 & 0.345 & 0.384 \\
$\mathrm{~N}_{\mathrm{H}} \mathrm{C}_{\mathrm{L}} \mathrm{R}_{\mathrm{L}}$ & 1.236 & 0.665 & 0.332 \\
$\mathrm{~N}_{\mathrm{H}} \mathrm{C}_{\mathrm{L}} \mathrm{R}_{\mathrm{H}}$ & 0.764 & 0.576 & 0.416 \\
$\mathrm{~N}_{\mathrm{H}} \mathrm{C}_{\mathrm{H}} \mathrm{R}_{\mathrm{L}}$ & 1.032 & 0.223 & 0.513 \\
$\mathrm{~N}_{\mathrm{H}} \mathrm{C}_{\mathrm{H}} \mathrm{R}_{\mathrm{H}}$ & 1.536 & 0.134 & 0.565 \\
\hline
\end{tabular}

TS $=$ Tensile strength, BFI $=$ Brittle fracture index and DT $=$ Disintegration time

Table 2. Individual and interaction effects of nature of binder, concentration of binder and relative density on the tensile strength, brittle fracture index and disintegration times for paracetamol tablets.

\begin{tabular}{llll}
\hline Variables & TS & BFI & DT \\
\hline $\begin{array}{l}\text { Independent } \\
\text { coefficient }\end{array}$ & & & \\
$\mathrm{N}$ & & & \\
$\mathrm{C}$ & 0.120 & -0.025 & 0.145 \\
$\mathrm{RD}$ & 0.523 & -0.286 & 0.112 \\
Interaction & 0.589 & -0.078 & 0.076 \\
coefficient & & & \\
$\mathrm{N}-\mathrm{C}$ & & & \\
$\mathrm{N}-\mathrm{RD}$ & 0.263 & -0.188 & 0.083 \\
$\mathrm{C}-\mathrm{RD}$ & -0.077 & -0.021 & -0.015 \\
\hline & 0.056 & -0.021 & -0.011 \\
\hline
\end{tabular}

$\mathrm{N}=$ Nature of binder, $\mathrm{C}=$ Concentration of binder, $\mathrm{RD}=$ Relative density, $\mathrm{TS}=$ Tensile strength, $\mathrm{BFI}=$ Brittle fracture index and DT $=$ Disintegration time. $\mathrm{p}<0.001$.

In comparing the formulations, the ranking of the individual (independent) coefficient values for the formulations on TS was $\mathrm{RD}>\mathrm{C}>>\mathrm{N}$, on BFI $\mathrm{C}>>\mathrm{RD}>\mathrm{N}$ and on DT $\mathrm{N}>\mathrm{C}>\mathrm{RD}$. All the individual effects on BFI were negative indicating that the values of the parameter decreased in all cases.

Increasing the concentration of the binder from $2.5 \%$ to $10 \% \mathrm{w} / \mathrm{w}$ led to an increase in the plastic deformation of the formulation during compression and subsequently to the formation of more solid bonds in the tablet [6] leading to an increase in the TS and DT of the tablet. However, the effect of $\mathrm{C}$ on the BFI was negative, indicating that the values of BFI for the formulation decreased with increase in binder concentration. This indicates that the presence of binder at interparticulate junctions facilitates plastic deformation for the relief of localized stresses [5, 6]. It is notable that the effect of $\mathrm{C}$ on BFI was significantly $(\mathrm{p}<0.001)$ higher than the effects of the other variables, $\mathrm{N}$ and $\mathrm{RD}$, showing its importance in determining the brittle properties of tablets.

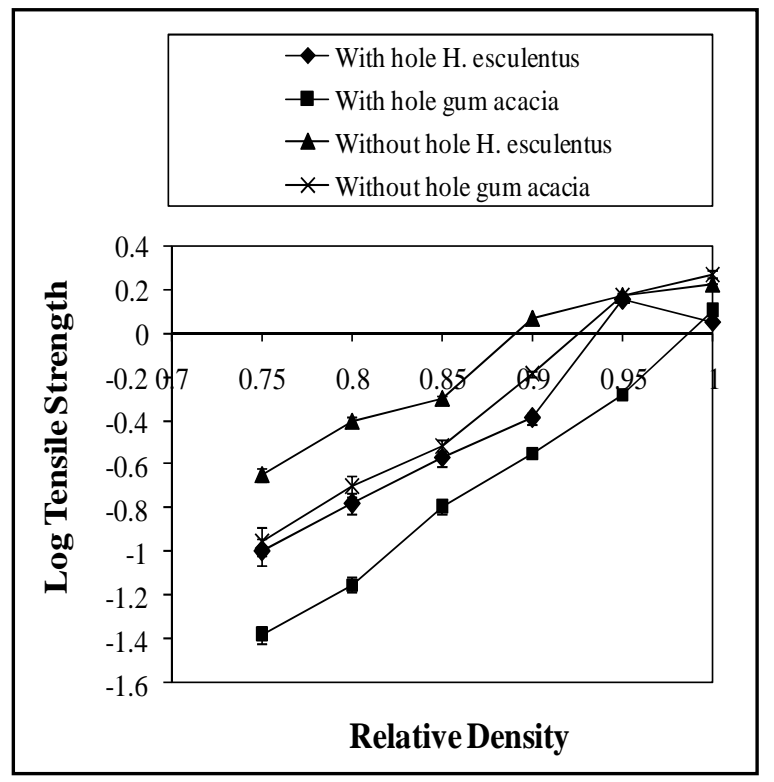

Figure 1: Log tensile strength versus relative density for paracetamol tablets containing $\mathbf{2 . 5}$ $\%$ w/w of binder

The RD had the highest effect on TS but the least effect on DT. Increasing the RD from 0.7 to 0.8 led to an increase in the TS and DT of the 


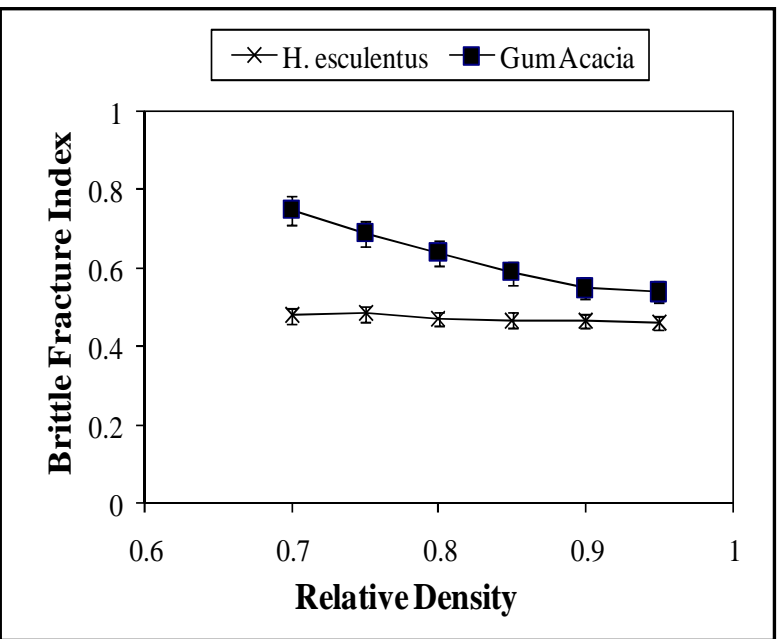

Figure 2: Brittle fracture index versus relative density for paracetamol tablets containing $2.5 \%$ w/w of binder

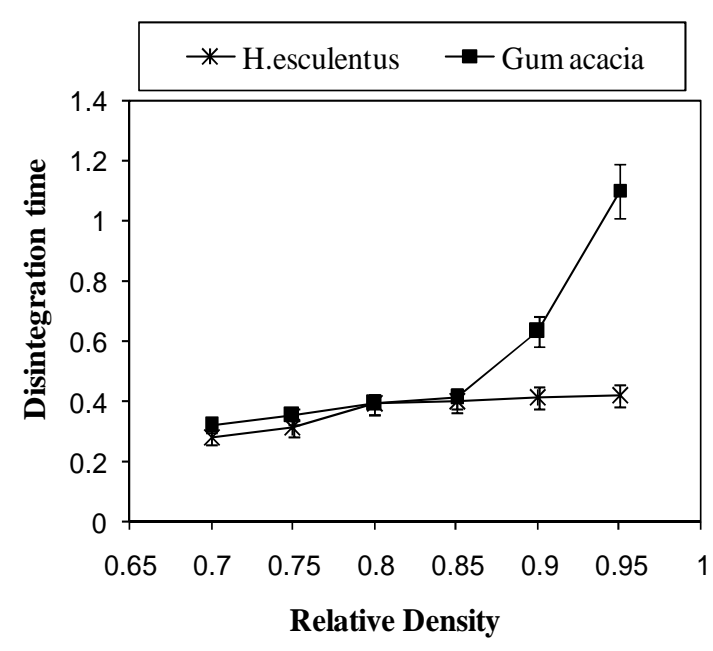

Figure 3: Disintegration time (minutes) versus relative density for paracetamol tablets containing $2.5 \%$ w/w of binder

tablet. The increase in TS may be attributed to the formation of more solid bonds between the particles as the RD of the tablet increases. Furthermore, the mucilages are forced into interparticulate spaces thereby increasing the area of contact between the particles leading to formation of additional solid bonds. This will result in a reduction in the size of the capillary spaces between the particles which reduces the rate of penetration of water into the tablet to effect bond separation thus increasing the DT of the tablets. This result is in agreement with those obtained by Odeku and Itiola [7] when comparing the effects of khaya gum and polyvinyl-pyrrolidone on the tensile strength, disintegration and dissolution properties of paracetamol tablets.

The influence of $\mathrm{N}$ on the TS and DT of the tablets was positive, indicating that tablets containing gum acacia as binder, which represented the high level of $\mathrm{N}$, had higher TS and DT than tablets containing Hibiscus esculentus mucilage. Thus, gum acacia is a stronger binding agent than Hibiscus esculentus mucilage in this particular context. However, all the tablets complied with BP 1998 specifications for disintegration. Hibiscus esculentus mucilage could therefore be useful as an alternative binding agent to produce tablets with particular TS and faster disintegration profile. On the other hand, the influence of $\mathrm{N}$ on BFI was negative indicating that Hibiscus esculentus mucilage produced tablets with lower BFI values than gum acacia. Thus, tablets containing Hibiscus esculentus mucilage, despite their lower bond strength, had better ability to relieve localized stresses compared to those containing gum acacia as binding agent [7].

The interaction coefficient values (Table 2) indicate the effect of the variables in combination. It can be seen that all the variables, $\mathrm{N}, \mathrm{C}$, and $\mathrm{RD}$, interacted with each other to alter the TS, BFI and DT of the tablets. The ranking of the interaction effects on TS and DT was N$\mathrm{C}>>\mathrm{N}-\mathrm{RD}>\mathrm{C}-\mathrm{RD}$ while that on BFI was $\mathrm{N}$ $\mathrm{C}>>\mathrm{C}-\mathrm{RD}=\mathrm{N}-\mathrm{RD}$. In all cases, the interaction between $\mathrm{N}$ and $\mathrm{C}$ had the largest effect on tablet properties, which suggests that RD had the most independent influence on the mechanical and disintegration properties of paracetamol tablets. Furthermore, statistical analysis showed that the interaction between $\mathrm{N}$ and $\mathrm{C}$ was significantly $(\mathrm{p}<0.001)$ higher than those between $\mathrm{N}$ and RD and those between $\mathrm{C}$ and RD. This is probably because the nature of binder determines the softness and plasto-elastic properties of the binder and in effect the amount of deformation the binder undergoes under high compressional forces [12]. The number of bonds formed will depend considerably on the concentration of binder employed [5,7]. Thus the nature and 
concentration of the binder employed in a formulation need to be carefully chosen to enable the production of tablets with adequate bond strength to withstand the rigors of handling.

\section{CONCLUSION}

The results obtained suggest that a change in the binder from gum acacia to $H$. esculentus would lead to a decrease in the tensile strength, disintegration and the lamination tendency of paracetamol tablets. Furthermore, an increase in relative density of the tablet and binder concentration resulted in tablets with higher

\section{REFERENCES}

[1] J.N. BeMiller, R.L. Whistler, D.G. Barkalow and C.C. Chen in R. L. Whistler and J. N. BeMiller (eds.). Industrial Gums, $3^{\text {rd }}$ Edition, Academic Press, New York. 1993, p 227-256.

[2] R.C. Woolfall, Soap Perfume Cosmet. 37 (1964) 965-970.

[3] O.A. Itiola, Pharm. World J. 8 (1991) 91-94.

[4] O.A. Itiola. and N. Pilpel, Pharmazie. 51 (1996) 987-989.

[5] O.A. Odeku. and O.A. Itiola, Trop. J. Pharm. Res. 2 (2003) 147-153. tensile strength and disintegration time, but lower brittle fracture index. The interaction between nature and concentration of mucilage binder had the highest effects on the mechanical and disintegration properties of paracetamol tablets. Thus, in tablet formulation, the nature and concentration of mucilage binder need to be carefully chosen during to obtain tablets of desired mechanical and disintegration properties. Furthermore, the results demonstrate that $H$. esculentus could be useful as an alternative binding agent to gum acacia, especially where faster disintegration is required and the problems of lamination and capping are of particular concern.

[6] O.A. Itiola and N. Pilpel, Int. J. Pharm. 31 (1986) 99-105.

[7] O.A. Odeku and O.A. Itiola, Pharm. Pharmacol. Commun. 4 (1998) 183-188.

[8] E.N. Hiestand, J.E. Wells, C.B. Poet and J.F. Ochs, J. Pharm. Sci. 66 (1977) 510519.

[9] S.K. Baveja, R. Ranga and A. Kagdish, Indian J. Pharm. Sci. 50 (1988) 89-92.

[10] O.A. Itiola and N. Pilpel, J. Pharm. Pharmacol. 43 (1991) 145-147.

[11] J.T Fell and J.M. Newton, J. Pharm. Sci. 59 (1970) 688-691.

[12] O.A. Itiola, Polytech. J. Sci. Tech. 1 (1990) 7-19. 